Jurnal Health Sains: p-ISSN: 2723-4339 e-ISSN: 2548-1398

Vol. 2, No. 5, Mei 2021

\title{
STANDAR KESELAMATAN DAN KESEHATAN KERJA (K3) WISMA ARIMBI DAN WISMA BIMA RUMAH SAKIT JIWA GRHASIA DAERAH ISTIMEWA YOGYAKARTA
}

\author{
Julian Dwi Saptadi, Machfudz Eko Arianto dan Muhammad Rafly Adha \\ Universitas Ahmad Dahlan (UAD) Yogyakarta, Indonesia \\ Email: julian.saptadi@ikm.uad.ac.id,machfudz.arianto@ikm.uad.ac.id dan aflyadha15@gmail. \\ com
}

\begin{tabular}{l}
\hline ARTIKEL INFO \\
\hline Tanggal diterima: 5 Mei 2021 \\
Tanggal revisi: 15 Mei 2021 \\
Tanggal yang disetujui: $25 \mathrm{Mei}$ \\
2021
\end{tabular}

Keywords:

implementation; service

standards; safety; health

\begin{abstract}
The implementation of hospital occupational health and safety service standards at Wisma Arimbi and Wisma Bima is still not optimal because there are still hospital occupational health and safety programs that have not been running optimally, such as uneven health checks. The purpose of this study was to see the application of occupational safety and health service standards at Wisma Arimbi and Wisma Bima in the Grhasia Mental Hospital, Special Region of Yogyakarta. This is a qualitative research with a case study approach. The sampling technique in this study was to use purposive sampling method with as many as 5 subjects. The data in this study were obtained from in-depth interviews. The safety and security of Wisma Arimbi and Wisma Bima are good. The hospital has a hospital occupational health and safety team, adequate PPE and a good working environment. However, there is a shortage of hospital occupational health and safety human resources where only one person is competent in the hospital occupational health and safety field, while other members have other main tasks (double jobs). Occupational Health Services at Wisma Arimbi and Wisma Bima are already in operation, such as providing additional food, sports facilities and health insurance. But the health check has not been maximal. The implementation of service standards at Wisma Arimbi and Wisma Bima has not been maximal, there are still some hospital occupational health and safety service standards programs that have not yet been implemented, such as uneven health checks, lack of fire protection facilities, and lack of competent officers in the OSH sector.
\end{abstract}

\footnotetext{
ABSTRAK

Standar pelayanan K3RS di Wisma Arimbi dan Wisma Bima masih belum optimal karena masih ada program K3RS yang belum berjalan dengan maksimal seperti pemeriksaan kesehatan yang belum merata. Tujuan penelitian ini untuk mengetahui Penerapan Standar Pelayanan Keselamatan dan Kesehatan Kerja pada Perawat di Wisma Arimbi dan Wisma Bima Rumah Sakit Jiwa Grhasia Daerah Istimewa
}

$\begin{array}{ll}\text { How to cite: } & \text { Dwi Saptadi Julian, et. al (2021) Standar Keselamatan dan Kesehatan Kerja (K3) Wisma Arimbi dan } \\ & \text { Wisma Bima Rumah Sakit Jiwa Grhasia Daerah Istimewa Yogyakarta. Jurnal Health Sains 2(5). } \\ & \text { https://doi.org/10.46799/jhs.v2i5.169 } \\ \text { E-ISSN: } & \text { 2723-6927 } \\ \text { Published by: } & \text { Ridwan Institute }\end{array}$


Yogyakarta. Jenis penelitian kualitatif dengan pendekatan studi kasus. Teknik pengambilan sampel pada penelitian ini adalah dengan menggunakan metode Purposive Sampling dengan sebanyak 5 subjek. Data dalam penelitian ini diperoleh dari wawancara mendalam. Keselamatan dan Keamanan Kerja di Wisma Arimbi dan Wisma Bima sudah baik. Rumah Sakit memiliki Tim K3RS, APD yang memadai dan lingkungan kerja yang baik. Namun terdapat kekurangan pada SDM K3RS dimana hanya satu orang yang berkompentensi di bidang K3RS, sedangkan anggota lainnya memiliki tugas pokok lain (double job). Pelayanan Kesehatan Kerja di Wisma Arimbi dan Wisma Bima sudah berjalan seperti pemberian makanan tambahan, terdapatnya sarana olahraga dan jaminan kesehatan. Tetapi pemeriksaan kesehatan belum maksimal. Penerapan standar pelayanan di Wisma Arimbi dan Wisma Bima belum maksimal, masih terdapat beberapa program K3RS yang belum berjalan seperti

Kata Kunci:

penerapan; standar pelayanan; keselamatan; kesehatan kerja belum meratanya pemeriksaan kesehatan, minimnya sarana proteksi kebakaran, dan kurangnya petugas yang berkompeten dibidang K3.

\section{Pendahuluan}

Data dari (RI, 2014) total kecelakaan kerja yang terjadi di Indonesia pada tahun 2014. Kecelakaan kerja menjadi salah satu masalah urgen di lingkungan rumah sakit. Hal ini diakibatkan karena rumah sakit merupakan suatu unit pelayanan kesehatan yang memberikan pelayanan pada semua bidang dan jenis penyakit. Oleh sebab itu rumah sakit dituntut untuk dapat menyediakan dan menerapkan suatu upaya agar semua sumber daya manusia yang ada di rumah sakit dapat terlindungi, baik dari penyakit maupun kecelakaan akibat kerja (Ivana et al., 2014).

Rumah sakit (RS) sebagai salah satu fasilitas kesehatan merupakan unit kerja yang kompleks. Kompleksitas dari unit kerja tersebut ada pada peralatan dan fasilitas yang digunakan, oleh sebab itu potensi bahaya yang terjadi bermacam-macam diantaranya adalah penyakit infeksi, kebakaran, radiasi, bahan-bahan kimia, gas-gas anestesi, gangguan psikososial (Ardi \& Hariyono, 2018). Rumah sakit mempunyai banyak potensi bahaya yang dapat mengancam jiwa dan kehidupan khususnya untuk karyawan di rumah sakit, para pasien dan para pengunjung yang ada di lingkungan rumah sakit (Gunawan, 2018).

Rumah Sakit Jiwa memiliki tugas menyelenggarakan dan melaksanakan pelayanan pencegahan, pemulihan dan rehabilitasi dibidang Kesehatan Jiwa (Keputusan Menteri Kesehatan Nomor 135/Menkes/SK/IV/78) (Putri, 2019). Rumah sakit jiwa merupakan fasilitas kesehatan terdepan dalam memberikan pelayanan kesehatan jiwa. Sesuai Undang-undang Nomor 44 tahun 2009 tentang Rumah Sakit, rumah sakit jiwa sebagai institusi pelayanan kesehatan juga menyediakan menyediakan pelayanan rawat inap, rawat jalan, dan gawat darurat (Hardoko, 2020).

Keselamatan dan kesehatan kerja rumah sakit adalah kegiatan untuk menjamin dan melindungi keselamatan dan kesehatan bagi sumber daya manusia rumah sakit, pasien, pendamping pasien, sehingga dibuat standar perlindungan bagi pekerja yang ada di Rumah Sakit untuk mencegah dan mengurangi risiko bahaya tersebut (Olii et al., 2019). 
Penerapan merupakan proses untuk mempraktikan sesuatu yang dipengaruhi oleh faktor internal dan faktor eksternal. Penerapan yang baik dipengaruhi oleh pengetahuan termasuk di dalamnya dukungan lingkungan dan regulasi yang diterapkan. Upaya penerapan $\mathrm{K} 3$ di rumah sakit menyangkut tenaga kerja, cara/metode kerja, alat kerja, proses kerja, dan lingkungan kerja yang meliputi peningkatan, pencegahan, pengobatan, dan pemulihan. Tenaga kesehatan yang sering berkontak langsung dengan pasien adalah perawat. Tingkat pengetahuan K3 perawat sangat penting dalam menjaga keselamatan pasien dan diri perawat itu sendiri sesuai dengan penelitian terdahulu bahwa didapatkannya hubungan bermakna antara tingkat pengetahuan perawat dengan tindakan keselamatan terhadap pasien (Sitompul, 2019).

Keselamatan adalah suatu tingkatan keadaan tertentu dimana gedung, halaman/ground, peralatan, teknologi medis, informasi serta sistem di lingkungan Rumah Sakit tidak menimbulkan bahaya atau risiko fisik bagi pegawai, pasien, pengunjung serta masyarakat sekitar. Keselamatan merupakan kondisi atau situasi selamat dalam melaksanakan aktivitas atau kegiatan tertentu. Sedangkan keamanan adalah suatu kondisi yang melindungi properti milik Rumah Sakit, sumber daya manusia Rumah Sakit, pasien, pendamping pasien, pengunjung, maupun lingkungan Rumah Sakit dari bahaya pengrusakan dan kehilangan atau akses serta penggunaan oleh mereka yang tidak berwenang. keamanan kerja adalah unsurunsur penunjang yang mendukung terciptanya suasana kerja yang aman, baik berupa materil maupun non materil (Sitompul, 2019).

Upaya pelayanan kesehatan yang diberikan pada SDM Rumah Sakit secara paripurna meliputi pelayanan promotif, preventif, kuratif dan rehabilitatif. Pelayanan Kesehatan Kerja bertujuan untuk peningkatan dan pemeliharaan derajat kesehatan fisik, mental dan sosial yang setinggi-tingginya bagi pegawai di semua jenis pekerjaan, pencegahan terhadap gangguan kesehatan pekerja yang disebabkan oleh kondisi pekerjaan, perlindungan bagi pekerja dalam pekerjaannya dari risiko akibat faktor yang merugikan kesehatan, dan penempatan serta pemeliharaan pekerja dalam suatu lingkungan kerja yang disesuaikan dengan kondisi fisiologi dan psikologisnya (Sitompul, 2019).

Kebakaran merupakan salah satu bencana yang mungkin terjadi di Rumah Sakit (Sanjaya \& Ulfa, 2015). Dimana akibat yang ditimbulkannya akan berdampak buruk sangat luas dan menyeluruh bagi pelayanan, operasional, sarana dan prasarana pendukung lainnya, dimana didalamnya juga terdapat pasien, keluarga, pekerja dan pengunjung lainnya. Untuk hal tersebut maka Rumah Sakit harus melakukan upaya pengelolaan keselamatan kebakaran. Pencegahan kebakaran adalah upaya yang dilakukan untuk mencegah terjadinya kebakaran di Rumah Sakit. Pengendalian kebakaran adalah upaya yang dilakukan untuk memadamkan api pada saat terjadi kebakaran dan setelahnya (Sitompul, 2019).

Menurut Sistem Informasi Rumah Sakit (SIRS) terdapat dua rumah sakit jiwa di Yogyakarta, yaitu Rumah Sakit Khusus Puri Nirmala dan Rumah Sakit Jiwa Grhasia (Hendriani \& Hadi, 2020). Rumah Sakit Jiwa Grhasia DIY merupakan sebagai Rumah Sakit kelas A dengan kepemilikan milik Pemerintah Daerah DIY (Esem, 2018). Layanan rawat inap Rumah Sakit Jiwa Grhasia merupakan layanan bagi penderita gangguan jiwa/fasilitas pelayanan kesehatan untuk pasien yang memerlukan perawatan rawat inap untuk waktu tertentu sebagai upaya adaptasi sosial secara bertahap sehingga pasien mampu hidup mandiri di lingkungan keluarga dan masyarakat. Jenis layanan meliputi: Pelayanan Psikiatris Intensif, Pelayanan Medis Psikiatris, Pelayanan Psikologi, Pelayanan Rujukan Internal 
(Penyakit Dalam, Saraf, Anak, Kulit kelamin, Gigi, Fisiotherapi), Rehabilitasi Mental.

Berdasarkan studi pendahuluan awal yang dilakukan peneliti dengan melakukan wawancara terhadap dua orang Perawat di Wisma Arimbi dan Wisma Bima Rumah Sakit Jiwa Grhasia Pada tahun 2019 sampai dengan bulan Agustus 2020 terjadi setidaknya tiga kecelakaan di Wisma Arimbi dan Wisma Bima karena menangani pasien dengan diagnosa gaduh gelisah. Penerapan standar pelayanan K3 di Wisma Arimbi dan Wisma Bima masih belum optimal karena masih ada program K3RS yang belum berjalan dengan maksimal, seperti pemeriksaan berkala yang belum menyeluruh.

\section{Metode Penelitian}

Jenis penelitian yang dilakukan adalah penelitian kualitatif dengan menggunakan pendekatan Studi kasus. Penelitian kualitatif merupakan suatu metode penelitian yang dapat digunakan untuk mendeskripsikan peristiwa, perilaku orang atau suatu keadaan pada tempat tertentu secara rinci dan mendalam dalam bentuk narasi (Mulyatini \& Yustini, 2021). Studi kasus ialah suatu serangkaian kegiatan ilmiah yang dilakukan secara intensif, terincidan mendalam tentang suatu program, peristiwa, dan aktivitas, baik pada tingkat perorangan, sekelompok orang, lembaga, atau organisasi untuk memperoleh pengetahuan mendalam tentang peristiwa tersebut (Lesmana \& Ayu, 2019). Penelitian ini dilakukan pada bulan Desember - Januari 2020-2021.

Subjek penelitian ini sebanyak 5 orang. penentuan subjek penelitian dilakukan dengan metode Purposive Sampling dengan ditentukan berdasarkan kriteria tertentu oleh peneliti itu sendiri (Lesmana \& Ayu, 2019). Adapun teknik pengumpulan data menggunakan data primer dan sekunder. Data primer didapat dari hasil wawancara mendalam dengan informan. Sedangkan data sekunder didapatkan dari jurnal mengenai penerapan standar pelayanan K3RS dan juga penelitian terlebih dahulu. Selain itu peneliti juga menggunakan standar-standar K3RS seperti dan Permenkes No 66 Tahun 2016 dan Keputusan Mentri No 1087 Tahun 2010 tentang standar K3RS.

\section{Hasil dan Pembahasan}

\section{A. Hasil Penelitian}

Kebijakan K3 di Rumah Sakit Jiwa Grhasia mengacu pada Permenkes No 66 Tahun 2016 tentang K3RS. Standar Operasional Prosedur (SOP) K3RS diberlakukan secara umum untuk seluruh Rumah Sakit, tidak hanya di Wisma Arimbi dan Wisma Bima walaupun di kedua wisma tersebut merupakan wisma untuk pelayanan pasien instensif. Hal ini dibuktikan dari kutipan wawancara berikut:

"SOP terkait di K3 diberlakukan secara umum di Rumah Sakit, tidak hanya di Wisma Arimbi dan Wisma Bima mulai dari pemakaian APD, interaksi dengan B3. Ketika ada kecelakaan, ada form pelaporannya, kemudian dilakukan investigasi. SOP K3 diterakpakan secara umum walaupun di Wisma Arimbi dan Wisma Bima merupakan pelayanan untuk pasien intensif." (Informan A).

Berdasarkan hasil wawancara, penerapan keselamatan dan keamanan kerja di Wisma Arimbi dan Wisma Bima sudah cukup baik, karena sudah ada Tim K3RS yang pernah mengadakan kegiatan K3 seperti test kebugaran, tersedianya APD, sarana proteksi kebakaran. Hal ini dibuktikan dengan kutipan wawancara berikut:

"Mungkin pendapat saya pribadi kalau terkait dengan peran $\mathrm{K} 3$ berdasarkan pengalaman memang ada satu dua yang tampak maksud saya ada petugas K3nya ada kegiatan terkait K3 juga kalau terkait dengan kegiatan yang sifatnya K3 yang 

Jiwa Grhasia Daerah Istimewa Yogyakarta

tersentuh ke kami memang ada satu dua misalnya tes kebugaran itu pernah dilakukan tapi belum semua baru kepala wisma dan beberapa perawat". (Informan D)

Hasil wawancara mengenai pemeliharaan perlengkapan keselamatan kerja sudah dilaksanakan oleh pihak Rumah Sakit. Wisma Arimbi dan Wisma Bima hanya menerapkan pelaksanaan keselamatan kerja seperti tersedianya APD level 2 berupa sarung tangan, masker medis atau face shield, kacamata google dan gaun. Hal ini dibuktikan kutipan wawancara berikut:

"Disini selalu menggunakan APD ya mas, APD level 2, pakai masker, gaun, handscoon, faceshield dan kacamata google. Ada tim IPSRS dan laundry yang merawat mas". (Informan B)

Pemeliharaan APD seperti baju kerja atau gaun dilakukan oleh laundry rumah sakit dan sarana prasarana di Wisma dipelihara oleh IPSRS (Instalasi Pemeliharaan Sarana \& Prasarana Rumah Sakit). Kondisi tempat dan lingkungan kerja di Wisma Arimbi dan Wisma Bima sudah cukup baik. Berikut hasil wawancaranya:

"Dari fasilitas sudah ada ruangan yang sudah aman artinya ruangan sudah ada sel besinya yang kedua dilihat dari kelengkapan proteksi bahaya seperti APAR, table kortait, helm keselamatan, telepon. Dan dipelihara oleh tim K3 dan IPSRS” (Informan A).

Perawat yang memberi pelayanan kepada pasien minimal 2 orang perawat dan jika ada pasien yang sedang krisis maka perlu 4 orang perawat dan dibantu oleh sekuriti. Untuk pasien kondisi krisis akan ditempat di ruang isolasi tersendiri agar keselamatan antara pasien dapat terjaga. Berikut hasil wawancaranya:

"Jadi kerjanya pertim, dimana setiap melakukan tindakan ke pasien minimal 2 orang yang akan masuk ke ruangan, kalau pasien krisis akan ditangani oleh 4 orang dan dibantu oleh sekuriti”. (Informan B)

Kecelakaan akibat kerja yang pernah terjadi di Wisma Arimbi dan Bima antara lain: dipukul, dicakar, terjatuh sampai terjadi fraktur. Ketika perawat mengalami kejadian cidera akan dilakukan pertolongan pertama ke UGD dan jika tidak mampu maka akan dirujuk ke rumah sakit lain. Kejadian ini dilaporkan kepada tim K3 Rumah Sakit kemudian ditindak lanjut untuk diinvestigasi oleh tim K3. Berikut kutipan wawancaranya:

"Pertama dia lapor keatasan, nanti melaporkan ke K3 berupa form kemudian kami dari tim K3 akan mencatat laporan tersebut kemudian akan diverifikasi , misalkan pada laporan itu dia hanya butuh first aid maka diruangan saja dilakukan pertolongan dan kami akan mengcrosscheck apakah ada cidera serius, tetapi kalau hanya kecelakaan kecil tidak harus dibawa ke RS. Pernah ada kecelakaan fraktur dibawa ke rumah sakit lain, tim K3 yang akan mengurus proses asuransinya sampai dia sembuh" (Informan A)

Berdasarkan wawancara dengan ketua Tim K3RS, tata letak di Wisma Arimbi sudah bagus, wisma tersebut terletak didekat jalan utama sehingga memudahkan untuk pengevakuasian apabila terjadi bencana. Sedangkan untuk wisma Bima terletak sedikit lebih jauh dari jalan utama, karena harus memasuki gang. Hal ini dapat dibuktikan dari hasil kutipan wawancara berikut:

"Kalau di arimbi sudah bagus, disana dibedakan untuk gaduh gelisah dan ada ruangan isolasinya kemudian ada model fiksasi untuk pasien yang masih gaduh gelisah dan akan dikendorkan apabila terjadi cidera, itu SOP khusus yang ada di Arimbi dan Bima. Wisma bima dibangun belakangan jadi letaknya tidak 
terlalu ideal karna harus masuk ke gang gang dan jauh dari jalan utama." (Informan A)

\section{B. Pembahasan}

Keselamatan dan Keamanan Kerja merupakan upaya yang wajib dilakukan oleh rumah sakit agar tidak menimbulkan bahaya atau risiko fisik bagi SDM dan terciptanya suasana kerja yang aman dan nyaman (Hasibuan et al., 2020). Standar keselamatan dan keamanan di rumah sakit bertujuan untuk mencegah terjadinya kecelakaan dan cidera serta mempertahankan kondisi yang aman bagi sumber daya manusia rumah sakit, pasien, pendamping pasien, pengunjung maupun lingkungan rumah sakit.

Secara keseluruhan perlengkapan keselamatan kerja sudah dilaksanakan pemenuhan oleh pihak rumah sakit. Rumah sakit menerapkan pelaksanaan keselamatan dan keamanan kerja seperti tersedianya APD berupa sarung tangan, masker medis, face shield, kacamata google, boots dan baju kerja atau gaun. Penelitian ini sejalan dengan penelitian di RSUD Datoe Binangkang Kabupaten Bolaang Mongondow yang menyatakan bahwa rumah sakit menyediakan APD dan memasang rambu-rambu mengenai kewajiban menggunakan APD di tempat kerja.

Kondisi lingkungan dan tempat kerja di Wisma Arimbi dan Wisma Bima cukup baik hal ini dibuktikan dari sarana prasarana yang cukup memadai mulai dari penyediaan APD yang cukup lengkap, terdapat rambu bahaya (safety sign) di area Wisma Arimbi dan Wisma Bima dan ruangan pasien yang sudah diberikan teralis sehingga meningkatkan rasa aman bagi perawat dan pasien lainnya. Pengawasan dan pemeliharaan APD juga sudah dilakukan secara rutin oleh tim Instalasi Pemeliharaan Sarana Rumah Sakit (IPSRS). Pengelolaan prasarana rumah sakit adalah suatu upaya yang dilakukan untuk mengetahui kelayakan penggunaan prasaran rumah sakit sehingga sumber daya manusia rumah sakit, pasien, pendamping pasien, dan lingkungan menjadi aman dan selamat (Arikhman, 2020).

SDM Rumah Sakit sudah mendapatkan pelatihan tentang K3RS yang diadakan setiap setahun sekali dimana dalam pelatihan itu terdapat materi yang mencakup dasar K3 tentang kebakaran, penggunaan APAR, B3, dan manajemen risiko. Pelatihan K3RS sangat penting dilakukan untuk setiap SDM Rumah Sakit agar mengurangi terjadinya kecelakaan, kerusakan dan segala bentuk kerugian baik terhadap manusia maupun yang berhubungan dengan peralatan/ tempat bekerja. Tim K3RS juga melakukan sosialisasi terkait pengkodean kunci ruang pasien. Hal ini bertujuan untuk mempermudah saat membuka ruangan pasien dan mengantisipasi jika terjadi keadaan darurat.

Program K3RS belum berjalan dengan optimal dikarenakan oleh kurangnya SDM K3RS dan anggaran yang terbatas. SDM di tim K3RS hanya terdapat satu orang saja yang berkompetensi di bidang K3RS sedangkan anggota lainnya hanya merupakan part time atau merangkap jabatan.

Berdasarkan hasil penelitian secara keseluruhan standar pelayanan keselamatan dan keamanan kerja yang ada di Permenkes Nomor 66 Tahun 2016 sudah terlaksana dengan cukup baik. Hal ini dapat dilihat dari tersedianya APD dan sarana lain yang dipelihara oleh tim IPSRS, adanya pelatihan K3RS dan terdepatnya rambu bahaya (safety sign) di area Wisma Arimbi dan Wisma Bima.

\section{Kesimpulan}


Penerapan Keselamatan dan Kesehatan Kerja (K3) Wisma Arimbi dan Wisma Bima sudah baik karena Rumah Sakit sudah memiliki Tim K3RS, terdapat APD yang memadai dan lingkungan kerja yang sudah baik serta perawat yang sudah diberikan pelatihan. Namun masih terdapat kekurangan pada SDM pada Tim K3RS dimana anggota tim K3RS hanya satu orang yang berkompentensi di bidang K3RS, sedangkan anggota lainnya hanya membantu karena memiliki tugas pokok di bidang lain. Selain itu keterbatasan anggaran juga menyebabkan tidak meratanya penyelenggaraan program K3RS kepada SDM Rumah Sakit.

\section{BIBLIOGRAFI}

Ardi, S. Z., \& Hariyono, W. (2018). Analisa Penerapan Budaya Perilaku Keselamatan Dan Kesehatan Kerja Di Rumah Sakit. Jurnal Fakultas Kesehatan Masyarakat, 12(1), 15-20. Google Scholar

Arikhman, N. (2020). Analisis Penerapan Keselamatan Dan Kesehatan Kerja Pada Program Keselamatan Kerja Di Rumah Sakit Umum Daerah Sungai Dareh. Jurnal Kesehatan Medika Saintika, 11(2), 237-246. Google Scholar

Esem, O. (2018). Perlindungan Hak Atas Pelayanan Kesehatan Bagi Orang Dengan Gangguan Jiwa Di Daerah Istimewa Yogyakarta Berdasarkan Undang-Undang Nomor 18 Tahun 2014 Tentang Kesehatan Jiwa. Unika Soegijapranata Semarang. Google Scholar

Gunawan, S. (2018). Kajian Hukum Tentang Tanggung Jawab Administrasi Rumah Sakit Terhadap Keselamatan Dan Kesehatan Kerja Ditinjau Dari Peraturan Menteri Kesehatan Nomor 66 Tahun 2016 Tentang Keselamatan Dan Kesehatan Kerja Rumah Sakit. Yuriska: Jurnal Ilmiah Hukum, 10(1), 34-49. Google Scholar
Hardoko, M. (2020). Analisis Persepsi Perawat Terhadap Prevalensi Perilaku Agresif Pasien Di Rumah Sakit Jiwa X. Jurnal Admmirasi, 5(1), 49-57. Google Scholar

Hasibuan, A., Purba, B., Marzuki, I., Mahyuddin, M., Sianturi, E., Armus, R., Gusty, S., Chaerul, M., Sitorus, E., \& Khariri, K. (2020). Teknik Keselamatan Dan Kesehatan Kerja. Yayasan Kita Menulis. Google Scholar

Hendriani, A. D., \& Hadi, E. N. (2020). Evaluasi Standar Promosi Kesehatan Rumah Sakit Di Rumah Sakit Umum Daerah Dr. Soekardjo Kota Tasikmalaya. Jukema (Jurnal Kesehatan Masyarakat Aceh), 6(1), 29-42. Google Scholar

Ivana, A., Widjasena, B., \& Jayanti, S. (2014). Analisa Komitmen Manajemen Rumah Sakit (Rs) Terhadap Keselamatan Dan Kesehatan Kerja (K3) Pada Rs Prima Medika Pemalang. Jurnal Kesehatan Masyarakat (EJournal), 2(1), 35-41. Google Scholar

Lesmana, R., \& Ayu, S. D. (2019). Pengaruh Kualitas Produk Dan Citra Merek Terhadap Keputusan Pembelian Kosmetik Wardah Pt Paragon Tehnology And Innovation. Jurnal Pemasaran Kompetitif, 2(3), 59-72. Google Scholar

Mulyatini, N., \& Yustini, I. (2021). Pengaruh On Shelf Availability Dan Gaya Hidup Terhadap Keputusan Pembelian (Suatu Studi Pada Konsumen Toko H. Junaedi Kawali Distributor Produk Merek Rabbani). Business Management And Entrepreneurship Journal, 2(4), 126140. Google Scholar

Olii, G., Pinontoan, O. R., \& Kawatu, P. A. T. (2019). Gambaran Penerapan Standar Pelayanan Keselamatan Dan Kesehatan Kerja Rumah Sakit (K3rs) Di Rsud Datoe Binangkang Kabupaten Bolaang Mongondow. Kesmas, 8(6). Google 
Julian Dwi Saptadi, Machfudz Eko Arianto dan Muhammad Rafly Adha

Scholar

Putri, M. R. (2019). Rumah Sakit Jiwa Tipe A Dikota Semarang Dengan Pendekatan Desain Healing Environment. Unnes. Google Scholar

Ri, K. (2014). Pedoman Pelaksanaan Stimulasi, Deteksi Dan Intervensi Dini Tumbuh Kembang Anak Ditingkat Pelayanan Kesehatan Dasar. Jakarta2012. Google Scholar
Sanjaya, M., \& Ulfa, M. (2015). Evaluasi Sarana Dan Prasarana Rumah Sakit Dalam Menghadapi Bencana Kebakaran (Studi Kasus Di Rs Pku Muhammadiyah Yogyakarta Unit Ii). Jmmr (Jurnal Medicoeticolegal Dan Manajemen Rumah Sakit), 4(2). Google Scholar

Sitompul, J. A. (2019). Konsep Penerapan K3 Oleh Perawat Di Rumah Sakit Bagi Orang Yang Berada Di Sekitarnya. Google Scholar

\section{Copyright holder:}

Julian Dwi Saptadi, Machfudz Eko Arianto dan Muhammad Rafly Adha (2021)

First publication right:

Jurnal Health Sains

This article is licensed under:

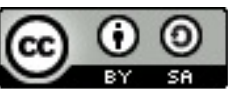

